\title{
Article \\ Characterisation of Electroplated Gold Coatings for Dental Applications: Estimation of Thickness Using Non-Destructive Electron-Probe Microanalysis Related to Plating Time
}

\author{
Terry R Walton
}

check for

updates

Citation: Walton, T.R

Characterisation of Electroplated

Gold Coatings for Dental

Applications: Estimation of Thickness

Using Non-Destructive

Electron-Probe Microanalysis Related

to Plating Time. Coatings 2021, 11, 874

https://doi.org/10.3390/coatings11080874

Academic Editors: Devis Bellucci and Roman A. Surmenev

Received: 21 June 2021

Accepted: 20 July 2021

Published: 22 July 2021

Publisher's Note: MDPI stays neutral with regard to jurisdictional claims in published maps and institutional affiliations.

Copyright: (C) 2021 by the author. Licensee MDPI, Basel, Switzerland. This article is an open access article distributed under the terms and conditions of the Creative Commons Attribution (CC BY) license (https:// creativecommons.org/licenses/by/ $4.0 /)$.
Department of Restorative and Reconstructive Dentistry, Faculty of Medicine and Health University of Sydney, Science Road, Camperdown, Sydney, NSW 2050, Australia; terry.walton@sydney.edu.au; Tel.: +61-410575844

\begin{abstract}
Objectives: This study aimed to measure non-destructively gold (Au) electrodeposited on a high-gold alloy by modulating coating time and comparing this to sputtering Au to known thicknesses. Methods: Au was electrodeposited (plated) on 11 high-gold alloy plates (A-K) at 2.8V between 20 and $220 \mathrm{~min}$. Seven Au strips were sputter coated on the same alloy to known thicknesses (range 50-500 nm). Energy dispersive X-ray spectroscopy (EDS) was used to measure minimal electron energy $\left(\mathrm{E}_{0}\right)$ required to penetrate $\mathrm{Au}$ coatings and generate $\mathrm{x}$-ray signals of $1 \%$ atomic palladium (Pd) from the underlying alloy for test samples and $\mathrm{Au}$ strips. \% Pd X-ray concentration at maximum $30 \mathrm{kV}$ was also obtained. The obtained signal-thickness relationship of known Au strip thicknesses was used to calculate Au thickness on the A-K samples based on two analytical relations. Energy dispersive X-ray fluorescence spectroscopy (XRF) was used as a complementary method to ensure coating thickness estimations were accurate. Results: EDS values for all reference and unknown thicknesses were obtained and verified with XRF. Correlating these signals with the Data Analysis Software and matching with known plating times allowed estimation of Au thickness of the unknown samples (range 27-425 nm). Estimated thicknesses were shown to have a linear relationship with plating time except for samples C-D, where there was an inverted relationship. Significance: A non-destructive method for measuring electrodeposited thickness of Au on high-gold alloys related to plating time was developed and verified. There is a linear relationship to Au thickness and plating time between 20 and $220 \mathrm{~min}$.
\end{abstract}

Keywords: high-gold alloys; gold electroplating; electron-probe microanalysis; energy dispersive X-ray spectroscopy; X-ray fluorescence spectroscopy; electrodeposit thickness; scanning electron microscopy; gold sputtering

\section{Introduction}

Gold $(\mathrm{Au})$ can be deposited on substrates by various mechanisms including electrodeposition, physical vapour deposition (sputtering) and evaporation. Au electrodeposition has the advantage of being achieved with relatively simple and inexpensive equipment in a near ambient pressure and temperature environment [1]. It is commonly used in the electronics and jewellery industries. Deposition of pure $\mathrm{Au}$ is not favoured in the electronics industry because the deposits are too soft. Instead gold-copper combinations increase strength and preserve the high conductivity of the deposits. Gold-indium and gold-rubidium combinations are favoured in the jewellery industry to modulate colour and lustre, and increase the deposit strength.

Neither lustre nor strength are essential when electrodepositing Au in dentistry. Tarnish and corrosion resistance, biocompatibility, aesthetics and durability (minimising breakdown of the deposit) are the important factors. The technique has been used, relatively infrequently, to enhance the aesthetics of removable, tooth-supported and implantsupported dental prostheses [2-5]. It has also been used to improve the porcelain-base 
metal alloy bond strength in metal-ceramic restorations [6] and to reduce the corrosion and subsequent gingival irritation and possible allergic reactions of any exposed alloy [4].

There is little information in the dental literature concerning the variables affecting electrodeposited Au coating (plate) thickness, durability and bond strength to the underlying alloy. Hardness and thickness of the coating have been identified as factors which are related to durability of the electrodeposited coating [2]. Mechanical strength, which is modulated by the grain size, will also affect durability [7]. The finer the grain size, the greater the mechanical strength of the deposit, both within it and in its attachment to the underlying metal substrate. Grain boundary strength is therefore determined by grain refinement mechanisms [7]. Crystalline grain size is controlled by current density, bath temperature and the additive amount of the metal in the aqueous electrolyte. Thickness could also impact on the fit of prostheses, although it has been stated that thicknesses up to $12.5 \mu \mathrm{m}$ have no clinical effect on fit [2].

Controlling current density is a practical way of controlling grain size and nucleation rate, with an increase in current density resulting in a finer-grained structure. However, a crossover is reached whereby an overpotential occurs, resulting in an increase in grain size [7].

Au sputtering can be used as an alternative coating technique and can be controlled to give reproducible and predictable thicknesses, but the expensive equipment involved renders the process impractical for dental applications. However, due to its accuracy and consistency, it can be used as a reference technique in research, as is reported in this study. Regarding electrodeposition, there is little information in the literature detailing the $\mathrm{Au}$ coating process regarding current, plating time and resultant thickness, with recommendations only to follow the manufacturer's instructions.

Metal coating thickness can be measured with both destructive and non-destructive techniques. The destructive technique gives an actual measurement of the thickness, but the sample is destroyed. The non-destructive techniques require little or no preparation of the sample and the sample remains intact [8]. Such techniques use electron-probe microanalysis. Accelerated electron or X-ray beams are directed at the coating and penetrate to a depth dependent on the energy of the accelerated beam. Collision of the electrons or X-rays in the beam with those in the sample results in the release and scatter of energy which is detected and analysed [9]. Part of the spectrum of this reflected energy is in the form of X-rays with specific characteristics dependent on the atomic make-up of the excited elements. It is apparent that the coating has been penetrated when X-rays from elements in the underlying material are detected. The thicker the coating, the more energy required to penetrate it.

The required energies are then analysed and correlated to thickness. These techniques use mathematical algorithms which include some assumptions to calculate an estimated coating thickness [10]. They are therefore classified as analytical techniques and the accuracy of measurements will be dependent on the validity of the algorithms used. Energy dispersive X-ray spectroscopy (EDS) and X-ray fluorescence spectroscopy (XFS) are such techniques. The difference between the two is the type of radiation hitting the sample. EDS uses an electron beam while XRF uses an X-ray beam. Accuracy in the order of $\pm 5 \%$ is typical for single layer coatings [11].

It is hypothesized that the resultant thickness of Au electrodeposited to a high-gold alloy at a constant current increases with plating time, and can be expressed by a mathematical formula.

This study aimed to determine parameters required to Au plate a high-gold alloy by electrodeposition to achieve a known thickness. Au was electrodeposited at a constant current on a high-gold alloy across varying coating times; and the resultant thickness was calculated with reference to Au deposits of known thickness created with the sputtering technique. 


\section{Materials and Methods}

A commercially available high-gold alloy $(75 \% \mathrm{Au})$ which is used to cast implant abutments and tooth-supported crowns in dentistry was chosen as the high-gold alloy for the study samples (V classic; Cendres+Métaux SA, Biel, Switzerland). Au was electrodeposited on 11 alloy plates $(n=11$, samples $A-K)$ obtained from the manufacturer (V classic; Cendres+Métaux SA, Biel, Switzerland) in a commercially available electroplating bath (Auroplatmini; Wieland Edelmetalle Gmbh, Pforzheim, Germany) filled with a plating solution (Aurogold C5 1.5gAu/L; Alphabond Dental Pty Ltd., Roseville, Australia) at constant voltage $(2.8 \mathrm{~V})$ for varying times ranging from $20 \mathrm{~min}$ and increasing in twenty minute increments to $220 \mathrm{~min}$. The composition of the alloy is documented in Table 1.

Table 1. Composition of the gold alloy V classic.

\begin{tabular}{cc}
\hline Element & Composition \% \\
\hline Gold-Au & 75 \\
Palladium-Pd & 19 \\
Silver-Ag & 1 \\
Copper-Cu & 0.44 \\
Zinc-Zn & 0.5 \\
Tin-Sn & 2 \\
Indium-In & 2 \\
Iridium-Ir & 0.01 \\
Ruthenium-Ru & 0.06 \\
\hline
\end{tabular}

Au thickness strips $(0,50,200,250,300,350$ and $500 \mathrm{~nm})$ were prepared on two reference sample plates of the same alloy by sputter-coating using an FHR MS 150 coater (Quorum Technologies, Sussex, UK) in a cleanroom (Chalmers MC-2 cleanroom, SP Technical Research Institute, Gothenburg, Sweden). The reference samples with the known Au thickness strips were used to assist in calculation of Au thickness of the study samples $(\mathrm{n}=11, \mathrm{~A}-\mathrm{K})$.

Energy dispersive X-ray spectroscopy (EDS) was used to estimate the thickness of $\mathrm{Au}$ strips $(n=7)$ sputtered on the two reference gold alloy plates, and the Au electrodeposited on the gold alloy samples $(n=11)$. XRF was used to cross-reference the thickness of the $\mathrm{Au}$ electrodeposited on the gold alloy samples that required electron acceleration energies greater than could penetrate the sample thickness with the available equipment.

The EDS analysis was performed using a X-Max $50 \mathrm{~mm}^{2}$ SDD detector (Oxford Instruments, Abingdon, UK) mounted on a Zeiss Supra 40VP scanning electron microscopy (SEM) system (Oxford Instruments, Abingdon, UK) and INCA Energy Analysis Software (Oxford Instruments NanoAnalysis, High Wycombe Bucks UK). For this EDS analysis, SEM settings included:

- $\quad 2-30 \mathrm{kV}$ electron acceleration voltage.

- "SE2" operating mode = secondary electron detection.

- Working distance (WD) of $8.5 \mathrm{~mm}$.

- Beam aperture $\# \mathbf{6}=120 \mu \mathrm{m}$.

- Magnifications of approximately $\times 100$.

The voltage of the EDS was modified to measure the palladium $(\mathrm{Pd})$ signal in the underlying alloy. The $\mathrm{Pd}$ signal $\left(\mathrm{E}_{0} \mathrm{Pd}\right)$ was defined as the minimal electron energy $\left(\mathrm{E}_{0}\right)$ required to detect the reflection of a X-ray signal of $1 \%$ atomic concentration of $\mathrm{Pd}$ present in the underlying alloy through the Au coating. In this instrument set up, the maximum acceleration voltage that could be used to obtain the Pd signal was $30 \mathrm{kV}$. When deposition coatings are thick, the electron acceleration to obtain the Pd signals required for analysis can exceed this $30 \mathrm{kV}$ limit. In these instances, although unable to directly measure the $\mathrm{E}_{0} \mathrm{Pd}$, the analysis software can be used to analytically extrapolate results. 


\subsection{Phase 1}

The $\mathrm{E}_{0} \mathrm{Pd}$ signals from the seven reference Au strips of known thickness (0-300 nm) across the two $\mathrm{Au}$ alloy sample plates and the samples of unknown thickness (A-K) were measured where possible up to the maximum $30 \mathrm{kV}$ acceleration mode. Following data acquisition, the $\mathrm{E}_{0} \mathrm{Pd}$ signals were then analysed with the Energy Analysis Software, the linear fitting coefficients extracted, and the obtained signal-thickness relationship determined for the known thicknesses of the gold strips and then used to correlate $\mathrm{Au}$ thickness for the study samples ( $\mathrm{n}=11, \mathrm{~A}-\mathrm{K})$

\subsection{Phase 2}

The $\%$ Pd concentration at the maximum constant acceleration mode of $30 \mathrm{kV}$ was also measured for the seven reference Au strips of known thickness (0-300 nm) sputtered on the reference alloy plates and the samples of unknown thickness (A-K). The obtained \% $\mathrm{Pd}$ concentration values of the reference $\mathrm{Au}$ strips were again analysed with the software and fitted to an asymmetric sigmoidal curve. Fitting constants of the $\% \mathrm{Pd}$ concentration of the samples A-K were then fitted to estimate the coating thickness.

\subsection{Phase 3}

When the electron acceleration required for penetration through the Au coating was above $30 \mathrm{kV}$, the analytically extrapolated results from the EDS method were cross referenced with energy dispersive $X$-ray fluorescence spectroscopy (XRF), to confirm the coating thickness estimations were accurate. To do so, a XRF instrument (Thermo Scientific Niton XL3t GoldD+XRF Analyser, Waltham, MA, USA) and compatible software for analysis (UniQuant, Omega Data Systems BV, Veldhoven, The Netherlands) was used. X-ray spectra from pure gold (99.9\%), a denominated sample of California Gold 297 (Cal $\mathrm{Au} 297,99.9 \% \mathrm{Au}$ ) and the V classic high-gold alloy (75\% Au) were used as references for calculating thickness of the Au coating by the UniQuant software.

\subsection{Phase 4}

The estimated $\mathrm{Au}$ thickness of the samples $\mathrm{A}-\mathrm{K}$ was then related to plating time.

\section{Results}

\subsection{Phase 1}

The $\mathrm{E}_{0} \mathrm{Pd}$ signals measured for the seven strips with known thickness of $\mathrm{Au}$ on the two reference plates are shown in Table 2. It can be seen that for thicknesses above $300 \mathrm{~nm}$, the $\mathrm{E}_{0} \mathrm{Pd}$ could not be measured with the available instrumentation.

Table 2. The $\mathrm{E}_{0} \mathrm{Pd}$ signals for the seven Au strips on the reference plates.

\begin{tabular}{ccc}
\hline Known Thickness of Au Strips on Reference Plates (nm) & $\begin{array}{c}\text { Measured } \mathbf{E}_{\mathbf{0}} \mathbf{P d} \\
\mathbf{k V}\end{array}$ \\
\hline 0 & 0 \\
50 & 6.2 \\
200 & 18 \\
300 & 22.5 \\
350 & 30 \\
500 & $*$ \\
\hline
\end{tabular}

* not measurable.

The $\mathrm{E}_{0} \mathrm{Pd}$ signals able to be obtained from the unknown thickness samples $(\mathrm{A}-\mathrm{H})$ are shown in Table 3. The values for samples I, J and $\mathrm{K}$ were not measurable, indicating they had thicknesses $>300 \mathrm{~nm}$. 
Table 3. Measured $\mathrm{E}_{0} \mathrm{Pd}$ of the unknown Au thickness samples A-H.

\begin{tabular}{cc}
\hline Sample & $\begin{array}{c}\text { Measured } \mathbf{E}_{\mathbf{0}} \mathbf{P d}, \\
\mathbf{k V}\end{array}$ \\
\hline A & 5.0 \\
B & 5.9 \\
C & 8.8 \\
D & 6.4 \\
E & 15.0 \\
F & 17.5 \\
G & 19.8 \\
H & 27.6 \\
I & $*$ \\
J & $*$ \\
K & $*$ \\
\hline
\end{tabular}

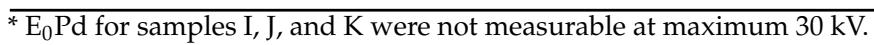

The linear fitting coefficients of the $\mathrm{E}_{0} \mathrm{Pd}$ signals from the seven $\mathrm{Au}$ reference strips with known thickness are depicted in Figure 1. The $\mathrm{E}_{0} \mathrm{Pd}$ signals obtained from the sample plates $(\mathrm{A}-\mathrm{H})$ with unknown Au thicknesses were plotted on the same curve (Figure 1) and thicknesses estimated shown in Table 4.

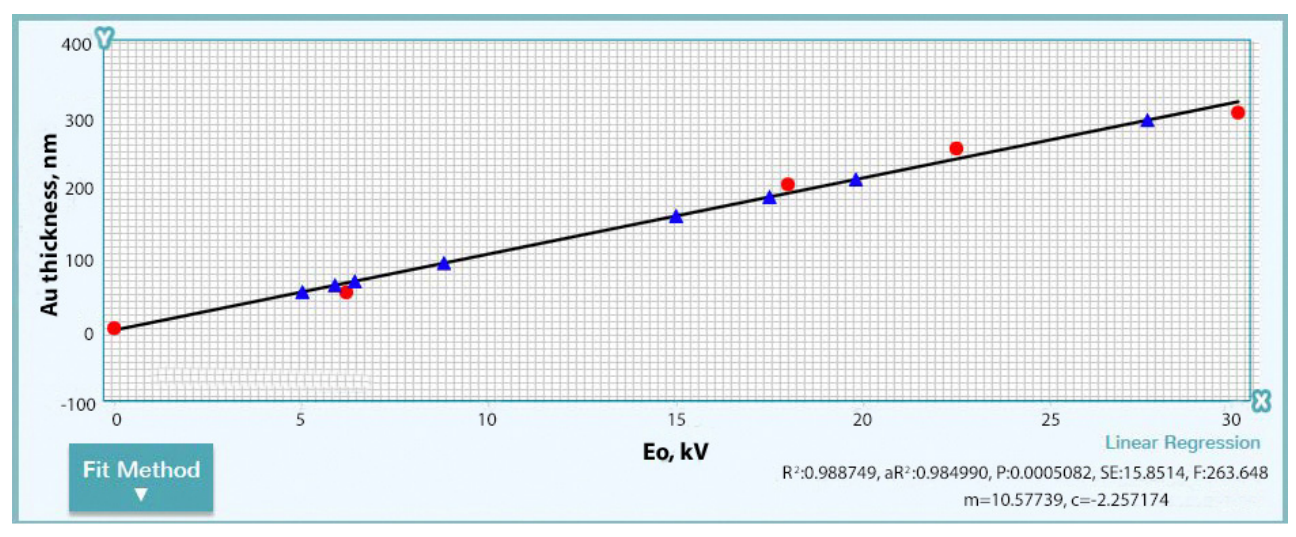

Figure 1. Linear fitting of the five measurable Au strip reference $\mathrm{E}_{0} \mathrm{Pd}$ measurements (red circles) and estimation of $\mathrm{Au}$ thickness based on measured $\mathrm{E}_{0} \mathrm{Pd}$ values for samples $\mathrm{A}-\mathrm{H}$ (blue triangles).

Table 4. $\mathrm{E}_{0} \mathrm{Pd}$ and estimated Au thickness for the samples $\mathrm{A}-\mathrm{H}$.

\begin{tabular}{cccc}
\hline Sample & $\begin{array}{c}\text { Plating Time } \\
\text { min }\end{array}$ & $\begin{array}{c}\text { Measured E } \mathbf{P d}, \\
\mathbf{k v}\end{array}$ & $\begin{array}{c}\text { Estimated Au } \\
\text { Thickness, } \\
\mathbf{n m}\end{array}$ \\
\hline A & 20 & 5.0 & 52 \\
B & 40 & 5.9 & 62 \\
C & 60 & 8.8 & 92 \\
D & 80 & 6.4 & 67 \\
E & 100 & 15.0 & 157 \\
F & 120 & 17.5 & 183 \\
G & 140 & 19.8 & 208 \\
H & 160 & 27.6 & 289 \\
\hline
\end{tabular}

The estimated thicknesses ranged from 52 to $289 \mathrm{~nm}$. Except for samples C and D, the thickness increased with plating time.

\subsection{Phase 2}

The $\%$ Pd concentrations at the maximum constant acceleration mode of $30 \mathrm{kV}$ measured for the seven reference Au strips are shown in Table 5. 
Table 5. \% Pd X-ray concentrations at $30 \mathrm{kV}$ for the 7 reference gold strips of known thickness obtained by sputtering.

\begin{tabular}{cc}
\hline $\begin{array}{c}\text { Deposited } \\
\text { Thickness, } \mathbf{n m}\end{array}$ & $\begin{array}{c}\text { Measured \% Pd } \\
\text { X-ray Concentration at } \mathbf{3 0 ~ k V}\end{array}$ \\
\hline 0 & 31.4 \\
50 & 23.3 \\
200 & 4.8 \\
300 & 2.6 \\
350 & 0.7 \\
500 & 0.5 \\
\hline
\end{tabular}

The fitting constants of these $\%$ Pd signals plotted on the asymmetric sigmoidal curve are shown in Figure 2. The \% Pd X-ray concentrations from the unknown thickness samples (A-K) were plotted on the same curve (Figure 2) and thicknesses estimated (Table 6).

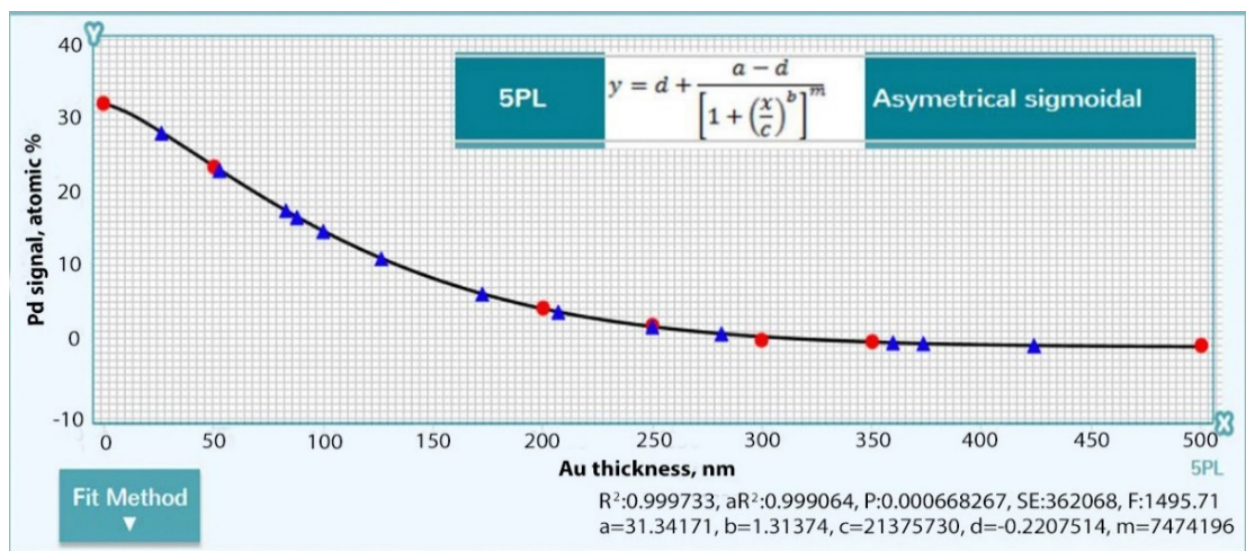

Figure 2. Asymmetric sigmoidal curve fitting of the XRF Au signal intensities of the known thickness of the 7 reference Au strips (red circles) and estimation of Au thickness based on measured \% $\mathrm{Pd}$ $\mathrm{X}$-ray concentration values at $30 \mathrm{kV}$ for samples $\mathrm{A}-\mathrm{K}\left(+\mathrm{C}^{*}\right.$ and $\left.\mathrm{D}^{*}\right)$ (blue triangles).

Table 6. Estimated Au coating thickness of samples A-K based on mathematically derived sigmoidal curve fitting constants from \% Pd X-ray concentration at $30 \mathrm{kV}$.

\begin{tabular}{ccc}
\hline Sample & $\begin{array}{c}\text { EDS Measured \% of Pd Xray } \\
\text { Concentration at } \mathbf{3 0 ~} \mathbf{~ k V}\end{array}$ & $\begin{array}{c}\text { Estimated Au Coating } \\
\text { Thickness, } \mathbf{~} \mathbf{m}\end{array}$ \\
\hline A & 27.5 & 27 \\
B & 22.7 & 53 \\
C & 14.8 & 101 \\
D & 17.5 & 84 \\
E & 6.7 & 173 \\
F & 4.3 & 207 \\
G & 2.4 & 250 \\
H & 1.5 & 281 \\
I & 0.4 & 359 \\
J & 0.3 & 373 \\
K & 0.0 & 425 \\
C & 11.2 & 127 \\
D $^{*}$ & 16.6 & 89
\end{tabular}

* Due to apparent anomalies in the estimations, repeat analyses of $\mathrm{C}$ and $\mathrm{D}$ were prepared. Additional estimations performed confirmed the anomalies.

The estimated thicknesses ranged from 27 to $425 \mathrm{~nm}$. Except for samples $C$ and D, the thickness increased with plating time. 
A comparison of the estimated $\mathrm{Au}$ thicknesses obtained by the two methods $\left(\mathrm{E}_{0} \mathrm{Pd}\right.$ signals and EDS of \% Pd concentration signals at $30 \mathrm{kV}$ ) is shown in Table 7.

Table 7. Comparison of estimated Au thickness for samples A-K obtained by $\mathrm{E}_{0} \mathrm{Pd}$ signals and \% Pd $\mathrm{X}$-ray concentration at $30 \mathrm{kV}$.

\begin{tabular}{|c|c|c|}
\hline Sample & $\begin{array}{c}\text { Estimated Au Thickness } \\
\text { through } \mathrm{E}_{0} \mathrm{Pd}\end{array}$ & $\begin{array}{c}\text { Estimated Au Thickness through \% Pd X-ray } \\
\text { Concentration at } 30 \mathrm{kV}\end{array}$ \\
\hline A & 52 & 27 \\
\hline B & 62 & 53 \\
\hline $\mathrm{C}$ & 92 & 101 \\
\hline $\mathrm{D}$ & 67 & 84 \\
\hline $\mathrm{E}$ & 157 & 173 \\
\hline $\mathrm{F}$ & 183 & 207 \\
\hline G & 208 & 250 \\
\hline $\mathrm{H}$ & 289 & 281 \\
\hline $\mathrm{I}$ & $*$ & 359 \\
\hline $\mathrm{J}$ & * & 373 \\
\hline $\mathrm{K}$ & * & 425 \\
\hline
\end{tabular}

* not measurable.

\subsection{Phase 3}

Even though the entire range of Au coating thickness could be estimated with the above methods, the measurements for the thicker coatings were less accurate due to the low $\mathrm{X}$-ray signal from the Pd. Therefore, XRF measurements were undertaken to cross-reference the coating thickness estimation calculated with EDS. The resultant X-ray spectra and $\mathrm{Au}$ signal intensity of the reference samples-pure Au (99.9\%), Cal Au (99.9\%Au) and V classic alloy $(75 \% \mathrm{Au}$ ) - are shown in Table 8 along with those for samples J and K. The calculated Au coating thickness of samples $\mathrm{J}$ and $\mathrm{K}$ is also shown. It can be seen that the measurements by EDS and XRF match within $10 \%$ for samples J and K.

Table 8. Au signal intensity from XRF and estimated Au coating thickness using XRF for reference samples and thicker coatings.

\begin{tabular}{cccc}
\hline Sample & Au \% & Au signal Intensity & $\begin{array}{c}\text { Estimated Au Coating } \\
\text { Thickness XRF, nm }\end{array}$ \\
\hline V classic alloy & 75.7 & 1668 & 0 \\
$99.99 \%$ Au & 99.9 & 2289 & $>7000$ \\
Cal Au 279 & 99.9 & 2332 & $>7000$ \\
J & & 1795 & $370(373)^{*}$ \\
K & 1825 & $460(425)^{*}$ \\
\hline
\end{tabular}

() * Estimations obtained from EDS \% Pd X-ray concentration.

\subsection{Phase 4}

The estimated film thickness has a linear relationship to plating time (except for samples $C-D$ and $C^{*}-D^{*}$, where there is an inverted relationship) (Figure 3 ). 


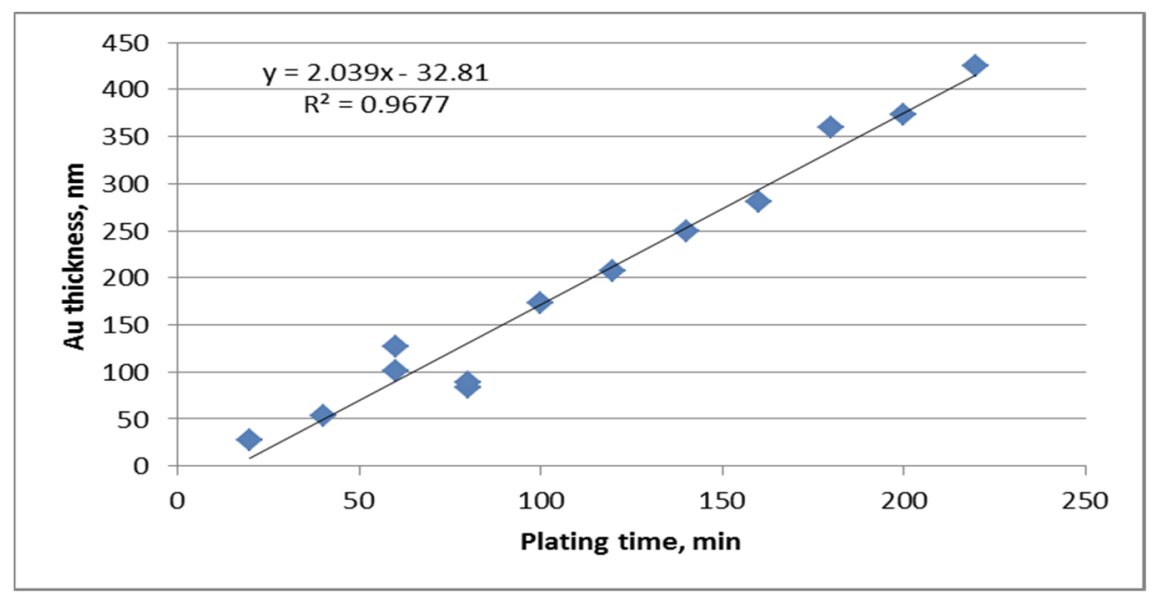

Figure 3. Au coating thickness (nm) based on Table 6 related to plating time.

\section{Discussion}

A non-destructive assessment of the electrodeposited Au coating on a high-gold alloy was undertaken by combining energy dispersive X-ray spectroscopy (EDS) and the application of two different analytical formulas with known Au thickness coatings obtained by sputtering. The predicted values are expected to be within $5 \%$ of the actual values of the sputtered plates with the designated software [11]. By cross-referencing the EDS values of the samples (A-K) with unknown Au thickness but known plating time, the estimated film thickness was subsequently shown to have a linear relationship to plating time except for samples $\mathrm{C}-\mathrm{D}$ and $\mathrm{C}^{*}-\mathrm{D}^{*}$, where there was an inverted relationship. (It is possible that the plating times of these two alloy plates were transposed in the laboratory.) Thus, highly predictable coating thicknesses can be obtained by varying the plating time. By keeping the voltage at $0.2 \mathrm{~mA}$, the grain size of the plate ensures a high mechanical strength and enhanced durability [7].

Varying Au plating thickness could enable different applications in dentistry. The masking power of $\mathrm{Au}$ is extremely high due to its density. Thus, relatively thin plating thicknesses can eliminate light reflection from underlying alloys conveying the desired $\mathrm{Au}$ lustre for aesthetic purposes. Plating times of $2 \mathrm{~h}$, giving an estimated thickness of $200 \mathrm{~nm}$ from the results in the present study, have proven to be effective clinically in satisfying aesthetic outcomes and maintaining durability over time [5]. Gold/gold hue abutments have been claimed to result in enhanced soft tissue aesthetics in implantsupported single crowns due to reflective properties [12]. Anodized titanium abutments have been introduced to simulate a desired Au lustre [13].

The relatively soft and distinctively coloured properties of the Au layer have been utilized by this author to act as a "fit checker" for tooth-supported prostheses, whereby scoring of the layer during try-in procedures can identify inaccuracies or bindings (asperities) in the tooth fitting surface.

It has been proposed that Au electrocoated to the abutment surface approximating the head of a dental implant could act as a gasket or sealing agent, thereby minimising percolation of bacteria at the implant-abutment junction, the microgap [14]. The effectiveness of any gasket would be especially influenced by the electrodeposit thickness. The results of this study show an increase in plating time from 2 to $4 \mathrm{~h}$ effectively doubles the estimated coating thickness. Further research is indicated to test this hypothesis.

In addition, the ductile and softer gold has been shown to reduce the frictional and galvanic corrosion (tribocorrosion) at the implant-abutment junction in an accelerated ageing study resulting in a decrease in release of titanium particles [14]. There is much controversy in the dental literature concerning the pathobiological effects of titanium release and its relationship to peri-implantitis [15]. 
The high cost of gold-based alloys and new fabricating technologies, such as computer assisted manufacture (CAM) and 3D printing, have spurred the development of alternative alloys for dental applications, especially in implant dentistry [16-18]. However, this has resulted in an increase in possible corrosion and pathological effects associated with peri-implant hard and soft tissues [19]. Au coating these alternative alloys may reduce associated corrosion. The anti-inflammatory reaction of Au has long been recognised in the medical field [20-23]. If the physiological and physical benefits of gold can be maintained in thin coatings and the pathological effects of alternate materials, suitable for these modern fabrication techniques, can be shielded by the gold coatings, this would be a significant development in ensuring that the benefits of implant dentistry are available to a broad range of "patients" and not just those in a very high socio-economic bracket. However, the replication of the measuring technique with other alloys requires further research.

There are several limitations to this study. Only one high-noble gold alloy was coated and one current density used. Further research is required to ascertain whether other alloys-particularly cobalt-chromium and stainless steel based—can be successfully Au plated and whether the linear relationship for coating thickness applies. Variations in current densities may be required to give a suitable grain size with adequate strength and bonding to the substrate alloy. In addition, different electroplating apparatuses and $\mathrm{Au}$ plating solutions may result in different plating thicknesses.

\section{Conclusions}

A non-destructive method for measuring electrodeposited thickness of Au on highnoble $\mathrm{Au}$ alloys related to plating time has been developed and verified. There is a linear relationship to Au thickness and plating time between 20 and $220 \mathrm{~min}$.

Funding: This research received no funding.

Institutional Review Board Statement: Not applicable.

Informed Consent Statement: Not applicable.

Data Availability Statement: Not applicable.

Acknowledgments: The author wishes to acknowledge Sarunas Petronis and Benny Lyvén of the SP Technical Research Institute of Sweden for their expertise in the technical operations of the EDS and XRF instrumentation and subsequent analytical interpretations of the data.

Conflicts of Interest: The author declares no conflict of interest.

\section{References}

1. Green, T.A. Electrodeposition for microelectronic, optoelectronic and microsystem applications. Gold Bull. 2007, 40, 105-114. [CrossRef]

2. Rogers, O.W. Gold-plating of cobalt-chromium. Aust. Dent. J. 1969, 14, 79-81. [CrossRef]

3. Livaditis, G.J.; Tate, D.L. Gold-plating etched-metal surfaces of resin-bonded retainers. J. Prosthet. Dent. 1988, 59, 153-158. [CrossRef]

4. Ozcelik, T.B.; Yilmaz, B. Galvanic gold plating for fixed dental prostheses. Eur. J. Dent. 2013, 7, 373-376.

5. Walton, T.R. The up-to-14-year survival and complication burden of 256 TiUnite implants supporting one-piece cast abutment/metal-ceramic implant-supported single crowns. J. Oral. Maxillofac. Implant. 2016, 31, 1349-1358. [CrossRef] [PubMed]

6. Daftary, F.; Donovan, T. Effect of electrodeposition of gold on porcelain-to-metal bond strength. J. Prosthet. Dent. 1987, 57, 41-46. [CrossRef]

7. Tang, H.; Chang, T.-F.M.; Chen, C.-Y.; Nagoshi, T.; Yamane, D.; Konishi, T.; Machida, K. Electrodeposition of gold alloys and the mechanical properties. In Novel Metal Electrodeposition and the Recent Application; Sone, M., Masu, K., Eds.; IntechOpen: London, UK, 2018; pp. 1-22. [CrossRef]

8. Giurlani, W.; Berretti, E.; Innocenti, M.; Lavacchi, A. Measuring the thickness of metal coatings: A review of the methods. Coatings 2020, 10, 1211. [CrossRef]

9. Castaing, R. In Adv Electron Electron Physics; Marton, L., Ed.; National Bureau of Standards: Washington, DC, USA, 1960; Volume 13, pp. 317-384.

10. Ng, F.L.; Wei, J.; Lai, F.K.; Goh, K.L. Metallic thin film depth measurements by X-ray microanalysis. Appl. Surf. Sci. 2006, 252, 3972-3976. [CrossRef] 
11. Nygard, K.; Hämäläinen, K.; Manninen, S.; Jalas, P.; Ruottinen, J. Quantitative thickness determination using X-ray fluorescence: Application to multiple layers. X-ray Spectrom 2004, 33, 354-359. [CrossRef]

12. Peng, M.; Zhao, W.-J.; Hosseini, M.; Zhou, W.-J.; Xiao, T.; Chuan, J.-L. Influence of restorative materials on color of implantsupported single crowns in esthetic zone: A spectrophotometric evaluation. Biomed. Res. Int. 2017. [CrossRef] [PubMed]

13. Wang, T.; Wang, L.; Lu, Q.; Fan, Z. Influence of anodized titanium abutments on the esthetics of the peri-implant soft tissue: A clinical study. J. Prosthet. Dent. 2021, 125, 445-452. [CrossRef] [PubMed]

14. Duarte Silva, M.; Walton, T.R.; Alrabeah, G.O.; Layton, D.M.; Petridis, H. Comparison of corrosion products from implant and various gold-based abutment couplings: The effect of gold plating. J. Oral. Implantol. 2020. [CrossRef] [PubMed]

15. Pierluigi, C.; Jemt, T. Are marginal bone level changes around dental implants due to infection? Clin. Implant Dent. Relat. Res. 2021, 23, 170-177. [CrossRef]

16. Kano, S.C.; Bonfante, G.; Huassne, R.; Siqueira, A.F. Use of base metal casting alloys for implant framework: Marginal accuracy analysis. J. Appl. Oral Sci. 2004, 12, 337-343. [CrossRef]

17. Øilo, M.; Nesse, H.; Lundberg, O.J.; Gjerdet, N.R. Mechanical properties of cobalt-chromium 3-unit fixed dental prostheses fabricated by casting, miliing and additive manufacturing. J. Prosthet. Dent. 2018, 120, 156e-1. [CrossRef]

18. Presotto, A.G.; Cordeiro, J.M.; Prosetto, J.G.; Rangel, C.; da Cruz, N.C.; Landers, R.; Barão, V.A.; Mesquita, M.F. Feasibility of 3D printed $\mathrm{CoCr}$ alloy for dental prostheses applications. J. Alloys Compd. 2021, 158171. [CrossRef]

19. Alrabeah, G.O.; Brett, P.; Knowles, J.C.; Petridis, H. The effect of metal ions released from different dental implant-abutment couples on osteoblast function and secretion of bone resorbing mediators. J. Dent. 2017, 66, 91-101. [CrossRef]

20. Yang, J.-P.; Merin, J.P.; Nakaon, T.; Kato, T.; Kitade, Y.; Okamoto, T. Inhibition of the DNA-binding activity of NF-kB by gold compounds in vitro. FEBS Lett. 1995, 361, 89-96. [CrossRef]

21. Jeon, K.-I.; Jeong, J.-Y.; Jue, D.-M. Thiol-reactive metal compounds inhibit NF-kB activation by blocking IkB kinase. J. Immunol. 2000, 164, 5981-5989. [CrossRef]

22. Zainali, K.; Baas, J.; Jakobsen, T.; Danscher, G.; Soballe, K. Particulate gold as an anti-imflammatory mediator in bone allograft-An animal study. J. Biomed. Mater. Res. Part A 2010, 95, 956-963. [CrossRef]

23. Rai, A.; Prabhume, A.; Perry, C.C. Antibiotic mediated synthesis of gold nanoparticles with potent antimicrobial activity and their application in antimicrobial coatings. J. Mater. Chem. 2010, 20, 6789-6798. [CrossRef] 